\title{
Problems of thermal protection of two-layer external walls with hinged facade systems
}

\author{
Ekaterina Ibe*, Galina Shibaeva, Svyatoslav Mironov, and Danil Litvin \\ Khakass Technical Institute of Siberian Federal University, Construction department, 655017, \\ Abakan, Khakassia, Russia
}

\begin{abstract}
Currently, in the Republic of Khakassia, much attention is paid to research aimed at reducing air pollution due to fuel combustion. In this aspect, the issue of increasing the energy efficiency of buildings is relevant. The use of ventilated facade systems with an air gap makes it possible to improve the energy efficiency class of buildings and modernize the facades. However, these facade systems have weak points that require detailed and high-quality study. Often, design solutions are used that are used in warm climates without taking into account the peculiarities of a cold climate - frequent changes in temperature, humidity, wind loads, and other influences, which can lead to negative manifestations. Facade systems with a ventilated air gap must provide the ability to monitor the operability of all system elements and, if necessary, carry out repair and reconstruction work with minimal operating costs. The article presents an analysis of the thermal properties of an external fence using a hinged facade structure. The influence of installation defects and heat-conducting inclusions on the heat-shielding properties of the building envelope is shown. It was determined that during operation the moisture-windproof membrane loses its vapor-permeable properties.
\end{abstract}

\section{Introduction}

The issues of heat-saving during the operation of buildings now play an important role, because thermal protection requirements are gradually increasing. At the same time, many buildings built with the advent of the first part of heat conservation standards currently have a low energy efficiency class. [1-3]

Table 1 shows the values of the required thermal resistance for external enclosing structures that meet the requirements of regulatory documents in the field of energy-saving.

After 2000, various heat-shielding materials were used in the construction of apartment buildings, and the building technology of multi-layer brick walls appeared.

\footnotetext{
* Corresponding author: katerina.ibe@mail.ru
} 
Table 1. The required values of the reduced resistance to heat transfer of the external walls

\begin{tabular}{|c|c|c|c|}
\hline \multirow{2}{*}{ Place } & \multicolumn{3}{|c|}{$\begin{array}{r}\text { The standard value of thermal resistance } \mathbf{R}_{\mathbf{0}},\left(\mathbf{m}^{2} \cdot \mathbf{K}\right) / \mathbf{W} \\
\text { (according to SNiP of various periods) }\end{array}$} \\
\cline { 2 - 4 } & The first part & The second part & The third part \\
\hline Abakan, Russia & 1.67 & 2.30 & 3.66 \\
\hline Novosibirsk, Russia & 1.13 & 2.12 & 3.71 \\
\hline
\end{tabular}

Currently, progressive technical and technological solutions have been actively introduced in construction. One of these is the ventilated air gap curtain wall system. [4] This system allows giving the building a modern architectural and expressive exterior. Also, the structure can ensure the reliability of facades through the use of new materials that are resistant to weathering and temperature extremes.

A major contribution to the study of heat-shielding properties of hinged facade systems was made by [5-11].

Authors [12], using the example of typical panel buildings, proved the effectiveness of the use of hinged facade systems in terms of reducing heat losses

The durability of mineral wool facades is up to 25 years, foam polystyrene facades are less - up to 20 years, due to the lack of vapor permeability of the insulation and structures compatible with it. During the period of seasonal freezing and thawing, the insulation accumulates a significant amount of moisture, which leads to inevitable crumpling of fibers and loss of thermal properties.

The considered design of the hinged facade systems has a lot of heat-conducting inclusions, and therefore it is heat-engineering heterogeneous. Additional problems during operation occur in the case of poor-quality installation of insulation layers.

\section{Methods}

The research methodology includes consideration of issues of epy ventilated facade systems installation and assessment of the influence of heat-conducting inclusions on the heat-shielding properties of the external wall. The first stage is a visual inspection of the building.

Since the bulk of the hinged facade system is occupied by insulation, the problems of high-quality installation of insulation have the greatest impact on the performance of the building's thermal envelope.

Mathematical modeling of the thermal regime of the structure in the cold season was carried out under the following boundary conditions:

- inside air temperature in the building $t_{\text {int }}=20^{\circ} \mathrm{C}$ (Russian standard GOST 304942011);

- outside air temperature $t_{\text {ext }}=-37{ }^{\circ} \mathrm{C}$ (Russian construction norm SP 50.13330.2012);

- heat transfer coefficient at the internal surface of the envelope $\alpha_{s i}=8.7 \mathrm{~W} /\left(\mathrm{m}^{2} \cdot \mathrm{K}\right)$ (Russian construction norm SP 50.13330.2012);

- heat transfer coefficient at the external surface of the envelope $\alpha_{s e}=23 \mathrm{~W} /\left(\mathrm{m}^{2} \cdot \mathrm{K}\right)$ (Russian construction norm SP 50.13330.2012) 


\section{Results}

The main effective factor in the use of hinged facade systems is the ability to save thermophysical properties as a result of the operation of the ventilated gap. In the conditions of the sharply continental climate of the Republic of Khakassia, a condensation plane forms in the multilayer outer walls, as a result of which mineral wool insulation loses its properties. However, due to the high air draft, pollutants in the form of dust and soot enter the ventilated air layer along with the atmospheric air, which settles on the surface of the insulation and can penetrate its thickness, deteriorating the properties. Also, in the presence of high air draft, the effect of the emission of insulation fibers occurs, especially with low-density materials.

The solution to the problem is to use a windproof membrane. However, the windproof membrane reduces the removal of moisture from the insulation, since the membrane has a high resistance to vapor permeation.

In the work, a heat engineering calculation of the external fence was carried out using hinged facade systems with the use (Fig. 1) and without the use of a moisture-windproof membrane (Fig. 2). The properties of the materials used in the outer wall are presented in the Table. 2.

Table 2. Characteristics of the materials.

\begin{tabular}{|c|c|c|c|c|}
\hline Number & Layer & Thickness, $\mathbf{m}$ & Density, $\mathbf{~ k g / \mathbf { m } ^ { \mathbf { 3 } }}$ & $\begin{array}{c}\text { Coefficient of thermal } \\
\text { conductivity, } \mathbf{W} /\left(\mathbf{m}^{\mathbf{2}} \cdot \mathbf{K}\right)\end{array}$ \\
\hline 1 & Masonry & 0.38 & 1800 & 0.7 \\
\hline 2 & Mineral wool & 0.12 & $120-170$ & 0.064 \\
\hline 3 & Cement mortar & 0.02 & 1800 & 0.72 \\
\hline 4 & $\begin{array}{c}\text { Windproof } \\
\text { membrane }\end{array}$ & 0.0001 & - & - \\
\hline 5 & Air gap & 0.05 & - & - \\
\hline 6 & $\begin{array}{c}\text { Composite } \\
\text { panel }\end{array}$ & 0.005 & - & - \\
\hline
\end{tabular}

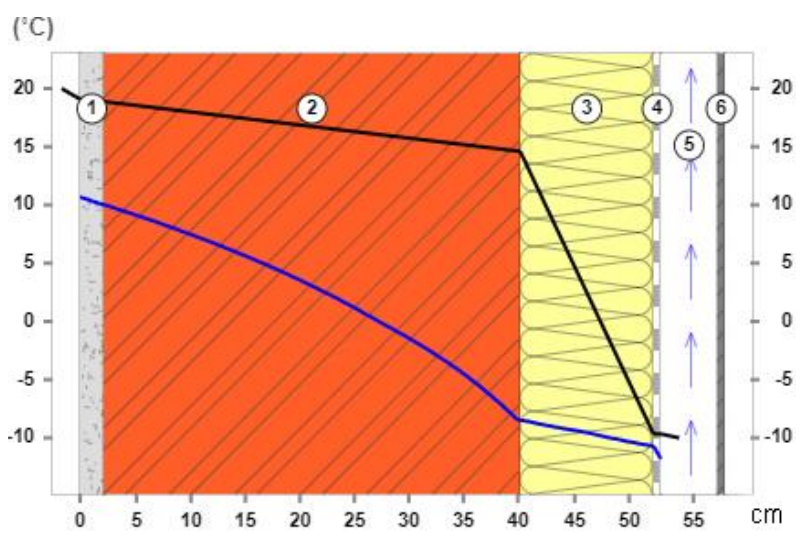

Fig. 1. Temperature distribution in the outer wall with a hinged ventilated facade using a moisturewindproof membrane 


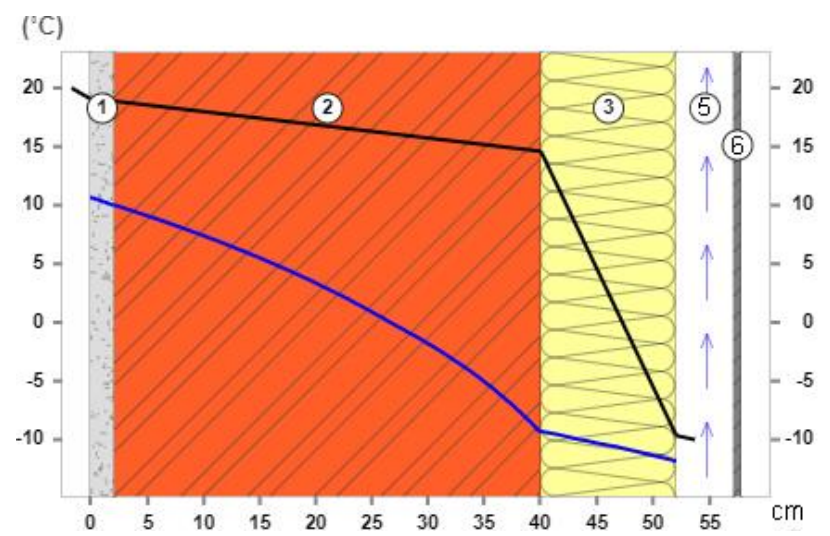

Fig. 2. Temperature distribution in the outer wall with a hinged ventilated facade without a moisturewindproof membrane

During the operation, the vapor permeability of the membrane will decrease due to its contamination (Fig. 3).

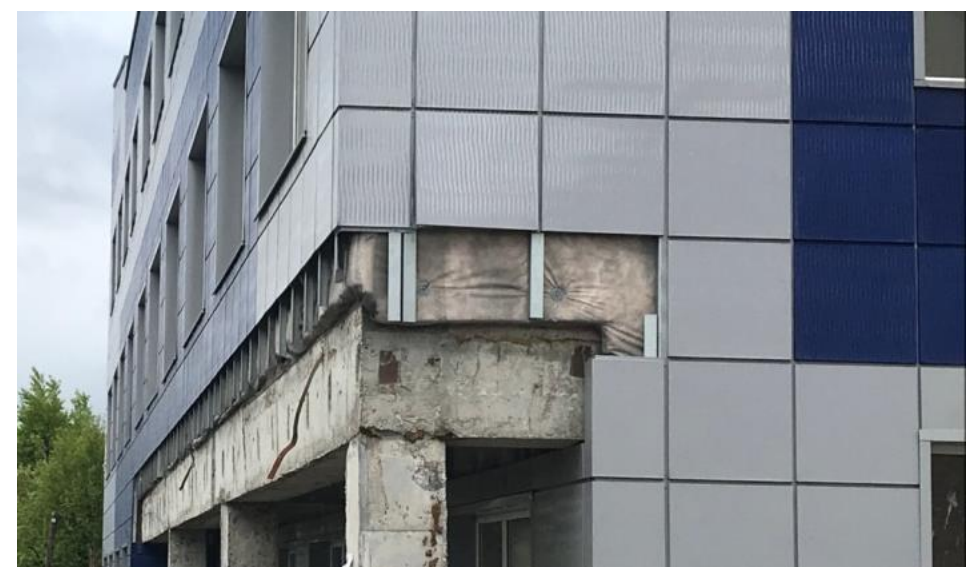

Fig. 3. Contamination of the moisture-windproof membrane during operation

The problems of the heat-shielding properties of the structures under consideration are primarily due to the presence of heat-conducting inclusions in the form of metal brackets. Also, heat-conducting inclusions are dowels for fixing insulation, window slopes, balcony slabs, outlets for fixing scaffolds.

Most facade systems have metal ties. Previous studies have shown the effect of heatconducting inclusions on the thermal protection of buildings. [14, 15] Calculation of the temperature fields of external walls with hinged facade systems for the climatic conditions of Abakan is shown on Fig. 4, 5.

The heat engineering heterogeneity of the outer wall is formed not only due to heatconducting inclusions from the fastening parts, but also from the poor-quality installation of insulation and the lack of bandaging the layers. [16]

Table 3 presents a computational analysis for the main types of heat losses of hinged facade systems. 
Table 3. The main types of heat losses of hinged facade systems.

\begin{tabular}{|c|c|}
\hline Type of heat-conducting inclusion & Heat loss, $\mathbf{W} / \mathbf{m}^{\mathbf{2}}$ \\
\hline Dowel plugs with metal spacer & 2.0 \\
\hline Steel brackets & 4.0 \\
\hline Aluminum alloy brackets & 5.5 \\
\hline Window slope & 2.5 \\
\hline
\end{tabular}

In general, defects during the installation of hinged facade systems include:

- Displacement of cladding panels vertically and horizontally;

- Exit of panels from the plane of the facade;

- Incorrect or poor-quality fastening of the cladding;

- Incorrect installation of insulation;

- Blocking the diffusion of moisture from the insulation.

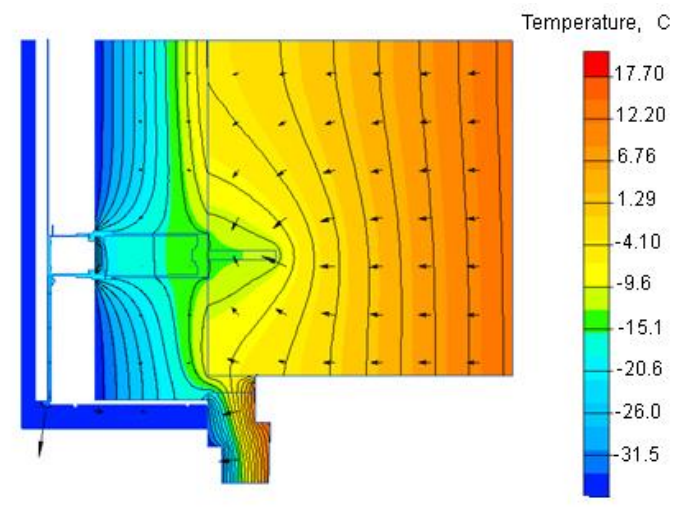

Fig. 4. Junction of the window frame to the wall with a hinged ventilated facade (horizontal section)

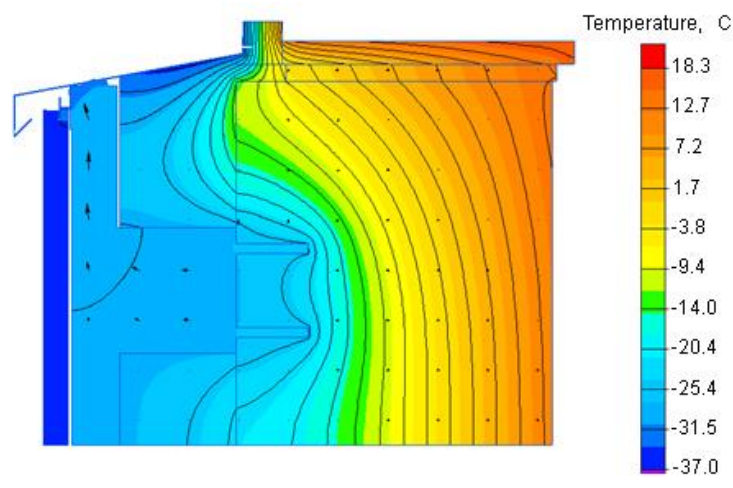

Fig. 5. Junction of the window frame to the wall with a hinged ventilated facade (vertical section)

Fig. 6 shows façade defects - gaps between heat-insulating plates.

Fig. 7 shows the temperature field of the external wall, taking into account the gaps between the heat-insulating plates. 


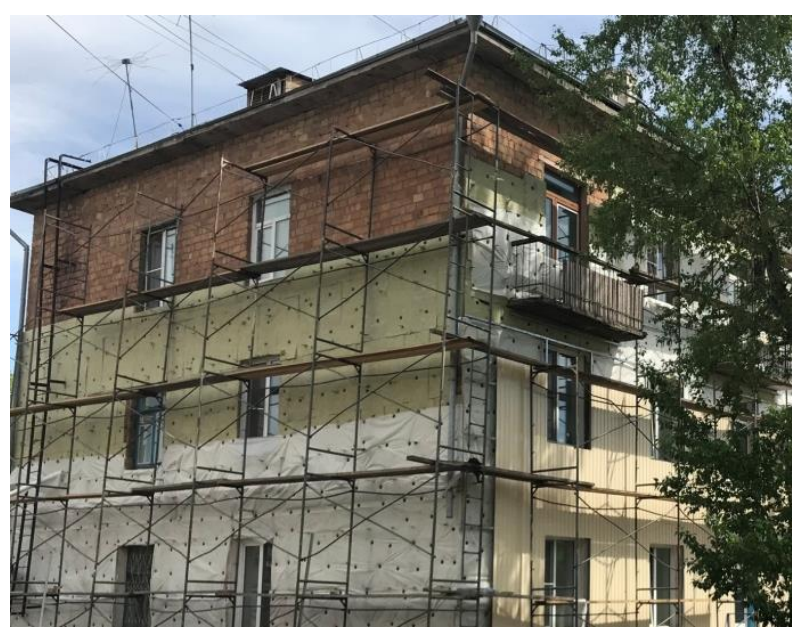

Fig. 6. Defects in the installation of hinged facade systems

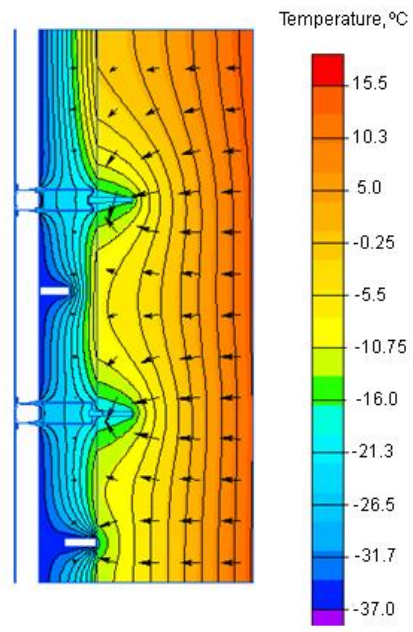

Fig. 7. Temperature field of the outer wall with a curtain ventilated facade with installation defects

You can see on Fig. 7 the displacement of the temperature isolines in the presence of voids and cracks at the joints of the insulation.

\section{Discussions}

Calculations have shown that the moisture-windproof membrane does no affect on the formation of a condensation plane in the outer wall. In the works [17-19] it is noted that the speed of air movement in the air gap within the range of up to $30 \mathrm{~m}$ is insignificant, which reduces the likelihood of mass emission of insulation fibers.

The influence of heat engineering uniformity on the heat-shielding qualities of wall systems is taken into account by introducing a correction factor (r) into the formula for calculating the thermal resistance. An analysis of the solutions implemented in the construction of residential buildings showed that this feature was not taken into account 
when developing the architectural section of the design documentation. Moreover, in most cases, the thickness of the insulation is taken to be greater than that required by the calculation. However, this does not lead to an increase in energy efficiency due to improper design of joints and parts. The junction zone of two enclosing structures affects the change in the heat flux passing through the outer fence. In the presence of cold bridges, the picture of the temperature field of the outer fence changes significantly.

Analysis of the results shows that the average temperature of warm-water inclusions in the winter period is $-15{ }^{\circ} \mathrm{C}$, while the dew point temperature shifts into the wall, which leads to a displacement of the condensation plane since the thermal conductivity coefficient of the insulation and the metal bracket differs hundreds of times.

Within the framework of the current regulatory documents, the calculation of the heat transfer resistance of the outer wall was carried out, taking into account the coefficient of heat engineering uniformity of the insulation $0.98 ; 0.95 ; 0.92$. As a result of the calculations, it became obvious that with a heat insulation homogeneity coefficient of 0.92 , the design of the outer fence ceases to meet the requirements of thermal protection. In the case of using a coefficient in the range of 0.65-0.75 (according to GOST R 54851-2011), the thickness of the insulation increases by 1.5-2 times, which significantly increases the estimated cost of construction. At the same time, the issue of heat-conducting inclusions with a given thickness of insulation is not solved.

Compliance with the installation technology, as well as high-quality sealing of window frames will, to some extent, reduce the heat engineering heterogeneity of the outer wall. In this case, the temperature field will have a non-uniformity at the points of attachment of the brackets.

The problem of eliminating cold bridges through the fastening parts can theoretically be solved by using a sealing material between the stone wall and the steel anchor for gradual heat transfer.

\section{Conclusions}

As a result of the research carried out, the following conclusions were formed:

1. Thermal properties of hinged facade systems differ significantly from multilayer walls due to a large number of fastening details. Also, problems arise in the event of incorrect installation.

2. The moisture-proof membrane quickly loses its vapor permeability properties due to contamination.

3. Taking into account the coefficient of thermal uniformity of the insulation will not lead to a positive result, since the thermal field in the nodes and joints will not change from this.

4. It is necessary to introduce regulatory requirements for the design of thermal protection, taking into account the modeling of the temperature angles of buildings and units of building structures.

\section{References}

1. D. Nemova, V. Murgul, V. Pukhkal, A. Golik, E. Chizhov, N. Vatin, Journal of applied engineering science. 12(1) (2014).

2. U. Ablayeva, N. Normatova, Problems of Architecture and Construction. 2(1), 59-62. (2019). 
3. S. V. Korniyenko, T. N. Astafurova, O. P. Kozlova, Energy Efficient Major Overhaul in Residential Buildings of the First Mass Series. In IOP Conference Series: Materials Science and Engineering, Vol. 753, No. 4, p. 042039. (2020, February).

4. I. Maltseva, A. Elokhov, V. Borisov, A. Verkhovskiy, Optimization of insulation in ventilated hinged facade systems. In MATEC Web of Conferences, Vol. 279, p. 03002. (2019).

5. V. Olshevskyi, E. Statsenko, T. Musorina, D. Nemova, A. Ostrovaia, Moisture transfer in ventilated facade structures. In MATEC Web of Conferences, Vol. 53, p. 01010. (2016).

6. V. G. Gagarin, N. Y. Plyushchenko, Construction: Science \& Education. 1, 1-5 (2015).

7. Y. B. Yavtushenko, M. V. Petrochenko, Magazine of Civil Engineering. 8, 38-45 (2013).

8. M. Petrichenko, A. Ostrovaia, E. Statsenko, Applied Mechanics and Materials. 725, 87-92 (2015)

9. S. Ryabukhina, T. Simankina, M. Koshkarova, N. Sokolovskii, O. Ryzhkov, Combined Thermal Insulating Module of Mounted Vented Facades. In MATEC Web of Conferences, Vol. 73, p. 02005 (2016).

10. P. Oleynik, Y. Korchagina, Organizational and technological sequence of the construction of an innovative type of hinged ventilated facade of a multi-storey building. In IOP Conference Series: Materials Science and Engineering, Vol. 869, No. 7, p. 072016. (2020, June).

11. Petrichenko M. et al. MATEC Web of Conferences. 53 (2016)

12. A. Gorshkov, N. Vatin, D. Nemova, A. Shabaldin, L. Melnikova, P. Kirill, Procedia Engineering. 117, 1080-1089 (2015)

13. M. Petrichenko, D. Nemova, E. Reich, S. Subbotina, F. Khayrutdinova, R. Schilling, V. Olshevskyi, Impact of Rustication Joints on Lightweight Insulation in Ventilated Facade Systems. In MATEC Web of Conferences, Vol. 73, p. 02007. (2016).

14. A. Kiselman, D. Portnyagin, E. Ibe, G. Shibaeva, Estimation of influence of heatconducting inclusions on thermal protection of filler constructions of buildings. In E3S Web of Conferences, Vol. 97, p. 04026 (2019).

15. O. Khalimov, G. Shibaeva, D. Portnyagin, K. Ibe, The improvement of aseismic horizontal frame's thermal insulations. In IOP Conference Series: Materials Science and Engineering, Vol. 365, No. 4, p. 042071. IOP Publishing. (2018, June).

16. A. E. Rusanov, A. K. Baiburin, D. A. Baiburin, V. Bianco, Magazine of Civil Engineering. 95(3) (2020)

17. E. Statsenko, A. Ostrovaia, A. Pigurin, Temperature and velocity conditions of air flow in vertical channel of hinged ventilated facade of a multistory building. In E3S web of conferences. Vol. 33, p. 02038 (2018).

18. M. Petrichenko, M. Petrochenko, Magazine of Civil Engineering. 26(8), 51-56 (2011)

19. M. Petrichenko, N. Vatin, D. Nemova, N. Kharkov, A. Korsun, Numerical modeling of thermogravitational convection in air gap of system of rear ventilated facades. In Applied Mechanics and Materials, Vol. 672, pp. 1903-1908. (2014).

20. N. Vatin, A. S. Gorshkov, D. V. Nemova, A. A. Staritcyna, D. S. Tarasova, Advanced Materials Research. 941, 905-920 (2014) 